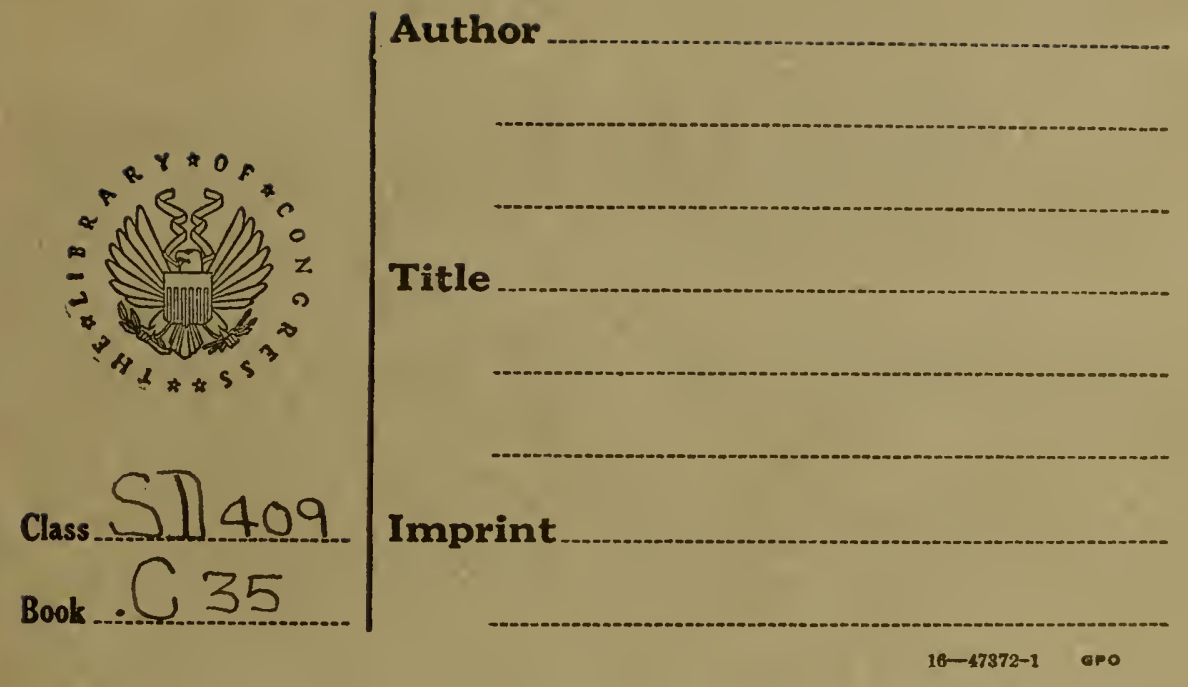


With Regards of the Author.

\title{
REPORT OF THE COMMIT'EE
}

-ox-

\section{MEDICAL TOPOGRAPHY, IETEOROLOGV,}

\section{ENDEMICS AND EPIDEMICS,}

\author{
MADE TO THE
}

MEDICAL SOCIETY OF THE STATE OF CALIFORNIA -AT THE-

ANNUAL SESSION, HELD AT SAN FRANCISCO, IN APRIL, 1883

Bx M. M. CHIPIIN, M. D.,

OF SAN FRANCISOO, CHAIRMAN OF COMHITTEE.

\section{Forest Preservation and Timber Cultivation.}

(Extracted from the Volume of Transactions of the Socrety.)

$$
\text { a) }
$$

SAN FRANCISCO:

Win'terburn \& Co., Printers and Electrotypers, 417 Clay Street, 1883. 



\section{REPORT OF THE COMMITTEE}

$-\mathrm{ON}-$

\section{MEDICAL TOPOGRAPHY, METEOROLOGY,}

\section{ENDEMICS AND EPIDENICS,}

MADE TO THE

MEDICAL SOCIETY OF THE STATE OF CALIFORNIA, -AT THE-

ANNUAL SESSION, HELD AT SAN FRANCISCO, IN APRIL, 1883

By M. M. CHIPMAN, M. D.,

OF SAN FRAXCISCO, ChaIRMAN OF COMMITTEE.

Forest Preservation and Timber Cultivation.

(Extracted from the Volume of Transactions of the Society.)

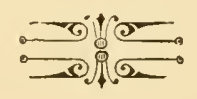

SAN FRANCISCO:

Wincerburx \& Co., Printers and Electrotypers, 417 Cliy Srreet, 1883. 


$$
\because 1]+301
$$

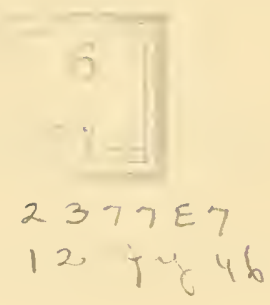




\title{
REPORT OF COMMITTEE
}

\section{MEDICAL TOPOGRAPHY, METEOROLOGY, ENIEEIICS, ETC.}

\section{Importance of Forest Preservation and Timber Cultivation.}

\author{
By M. M. CHIPMAN, M. D., Chairman.
}

Mr. President and Members of the Medical Society of the State of California: After the earth had performed its annual cycle for an iucomputable period, during the cooling off process, the mighty convulsions of conflicting elements, the gradual formation of soil upon its surface, the development of herb and fruit, and of animal life adapted to his uses and control, then was man created, or, as Mr. Darwin would say, developed, and given dominion over every living thing that moveth upon the earth; and the first commandment received from his Creator was: "Be fruitful and inultiply and replenish the earth, and subdue it." And as we examine through the pages of history, whether among the nations who have been conversant with the Sacred Law and Record, or of those who were unacquainted with the Hebraic and Christian systems, we find that the highest physical development, the farthest advance in civilization, and the greatest national power have been attained by those branches of the race who have appeared to be most earnest in carrying out the original injunction. And of the leading men and great thinkers of all ages, those who have been most venerated and who have earued and received most of the enduring gratitude of their fellow-men, have either been discoverers of additional resources, or organizers of movements in the same general direction of accumulation and advancement; and at this period of human existence no one who claims to be in sympathy with the cultivated humanitarian sentiment of the age, even though not venerating its source, will dissent from the binding force of the vital principles enunciated in the great fundamental law.

If we institute inquiry as to what this last and highest order of animated creation has accomplished in compliance with the great trust devolved upon him, we shall find that a great deal of energy and capacity have been displayed in certain directions; that his seed has greatly multiplied, and that his suçcessors have spread over all the inhabitable parts of the continents and to the isles of the sea; that he has subjugated the animal kingdom and 
reduced it to his will; and has from the bowels of the earth brought forth the metals and moulded them to his purposes; has brought under cultivation a vast area of earth's surface; and that throughout the whole world we find the results of his toil, the monuments of his intelligent labor, and the specimens of his inventive genius and skillful handiwork; in the great cities of his building; in his massive and beautiful palaces; his immense and numerous systems of public improvement; and in the ingenious and complicated devices for the elimination of force, the propulsion of conveyances, and the transmission of intelligence, whereby the whole civilized world is brought into immediate intercommunication and into close commercial and social relation and interdependence; and to this we may add the many appliances for human comfort, the numerous provisions for the maintenance and care of those who are unable to maintain and care for themselves; a high development of art; great advancement in the several sciences, and a comparative general diffusion of education and knowledge. But if we examine farther into the events of the past, and as to the early and present condition of this vice-royal domain, we shall find that this high steward has been in some respects, to our infinite regret, most derelict and culpable, as the terms of his dominion whilst charging him with the subjugation of the earth in nowise gave permission to destroy any part thereof; on the contrary, the injunction to mnltiply and replenish as certainly enjoined the principle of conservation, as the lessening in any degree the earth's population-sustaining resources, would to the same extent defeat the primary injunction itself, at whatever future period the population might become so numerous as to require the full measure of its productive capacity. And yet the comparison of ancient history and geography with the accounts of modern travelers and scientists, show that the space of the earth's surface, embracing Northern Africa, Southern and Eastern Europe in part, and Western and Central Asia, that vast central region in which the history of the race had its commencement, and throughout which, in different sections and regions, alternately existed the most populous and most advanced nations of their times, the dominating empires of their respective ages, where were exhibited a display of regal magnificence and splendor unequaled in modern times, has been changed by the occupancy and acts of man himself, either to utter barrenness, in some regions, or in other parts to conditions in which the soil is eapable of sustaining only a sparse and impoverished population; that those countries in which the great armies of the ancient Assyrians and Persians, and of the Crusaders and Tartars, in later ages, could, without an organized commissariat, secure adequate supplies in long marches, in our times would scarcely afford forage for a single regiment, the outlines and remains of broken and decayed internal improvements and the ruins of deserted cities being the only visible evidence of the former fertility, populousness, and opulence.

The late Hon. George P. Marsh, in his work, "The Earth as Modified by Human Action," says:

"It appears, then, that the fairest and fruitfulest provinces of the Roman Empire, precisely that portion of terrestrial surface, in short, which about the commencement of the Christian Era.was endowed with the greatest superiority of soil, climate, and position, which had been carriea to the highest pitch of physical improvement, and which thus combined the natural and artificial conditions best fitting it for the habitation and enjoyment of a dense 
and highly refined and cultivated population, are now completely exhausted of their fertility, or so diminished in productiveness, as with the exception of a few favored oases that have escaped the general ruin, to be no longer capable of affording sustenance to civilized man. If to this realm of desolation we add the now wasted and solitary soils of Persia and the remoter East, that once fed their millions on milk and honey, we shall see that a territory larger than all Europe, the abundance of which sustained, in bygone centuries, a population scarcely inferior to that of the whole Christian world of the present day, has been entirely withdrawn from human use, or at best is thinly inhabited by tribes too few in numbers, too poor in superfluous products, and too little advanced in culture and the social arts to contribute anything to the geueral moral and material interests of the great commonwealth of man."

It is sad to contemplate that this immense region, which at the advent of the human race was the most important, considering climate and productive resources, of any equal conterminous space on the earth's surface, can never be restored to sustain again its myriad population, or to be the theater of like busy scenes or great events; and it would now appear, in the light of the present, that the woes and desolation denounced by certain of the $\mathrm{He}$ brew prophets against the powerful nations of antiquity, were just in accordance, measure for measure, with their own improvidence and terrestrial destructiveness. But if we trace this matter still farther we shall ascertain that this destructive tendency has not been confined within the regions which were the seat of ancient empire, but that other parts of Asia have also suffered; that portions of Europe which were comparatively barbarous and uncultivated at the commencement of the Christian Era, have since been worn out and materially deteriorated both in soil and climate; that parts of Africa, beyond the northern countries referred to, have been made poorer by man's occupancy, and other parts allowed to become waste from neglect and lack of protection; and that even both divisions of the continent last opened to the settlement of the cultivating races have already begun to ex hibit, visibly, in certain sections, the deteriorating effects of their presence.

And having gone through and collated the works of the available authors upon this subject, $\{$ estimate as the sum of their statements that the total lessening of the earth's productive resources, from the advent of man to the present time, is fully equal to and perhaps may be in excess of one-third of its original population-sustaining capacity, and tlat principally through the wastefulness and incompetence of its human occupants. And were we to calculate the future of the race by its past history, considering the present rate of increase of population, and that the period must soon arrive when the whole of the earth's surface will be in possession of a population necessarily dependent upon agriculture as its source of food-supply, we would reach the conclusion that the acme of its existence is not far in advancewhen through the decadence and degeneration of the following centuries it would more rapidly retrograde to a condition equivalent to its prehistoric existence.

It is supposed that the torrid and temperate regions of primeval earth were mostly wooded, and that the clearing of the land to make room for more needed products was one of the first tasks of subjugation; but subsequently, as human settlements increased and extended, forest fires grew in frequency, and with the devastations of war and the uses for building and 
fuel of large cities, and from other causes, to a great extent, carelessness, wantonness, and a lack of forethought, the earth has been so far stripped of its timber growth as to not only cause scarcity in many parts for building and other domestic uses, but with even much more serious result, it has been demonstrated that the excessive forest destruction has been the chief factor in effecting the great detrimental changes in climate and productiveness to which the earth has been subjected.

Charles P. Daly, L.L.D., President of the American Geographical Society, in his annual address before that society for the year 1880 , made the following statement:

"The extreme dryness and consequent lack of moisture for the fertilization of the fields in parts of India and China, hitherto fruitful and thickly populated, is attributed to the wanton destruction of the forests on the hillsides, the observations made by Mr. Hilliard, in 1879, in a visit to the famine-stricken province of Shan $\mathrm{Si}$, in China, being confirmatory of that view."

The Tartar province of Great Bucharia, only fifty years ago, was a very beautiful, fertile, and productive country, but since that time it has been stripped of its forests by injudicious cleariug and by fire, during the ravages of a civil war, and the consequences are that the water-courses are dried up, the irrigating canals are empty, and the moving sands of the neighboring deserts being no longer restrained by the barriers of forest are every day gaining upon it, and the prospect is, will finish by transforming that whole country into a desert as desolate and solitary as those from which the sands are now drifting.

The Russians, in the conquest of the Caucassus, destroyed some of the forests, which served as protection to the contending Circassians, and in so doing changed those districts into a desert.

Spain, which three centuries and a half ago was the richest and one of the most powerful nations of Europe, owes much of her decadence to the loss of productiveness of her soil, and the consequent impoverishment of her people from the excessive denudation of her territory.

In France, extensive tracts of country, which a thousand years ago consisted of alternate woodland and fertile meadow and farming lands, have. by being stripped bare, become barren and incapable of sustaining but a small proportion of their former population; and Italy has large tracts of the same character, and from the same cause; and several other countries of Europe are also known to have sustained similar loss in a greater or less proportion, and probably there is not a country in that geographic division which has not suffered more or less deteriorating effects from this same cause.

Great damage has been sustained in Switzerland, in France, and in Italy, in the mountain districts and on the level lands adjacent, on account of the washing and abrasion of the sloping lands, the soil, rocks, and gravel beiug carried down to cover and ruin the valleys, because of the clearing off from about the sources of the streams.

In the Italian provinces of Parma and Lombardy, where formeriy the crops were pretty well assured, the clearing of the Appenines has material- 
ly changed the summer climate, the sirocco prevailing of late years to the great injury of the harvests and vineyards, and some seasons completely ruining the crops.

In some parts of Italy, of France, and Swizerland, the Spring season has been rendered much more backward and more subject to late frosts by the felling of forests which had previonsly sheltered from the cold winds, which now stunt the vegetation and materially lessen the certainty and success of some kinds of crops; and in other European countries, in some parts of the United States, and in other parts of the world, similar results have been observed.

In South Africa, great changes have taken place in the meteorologic conditions within a comparatively recent period, on account of excessive clearing, the country having become much more subject to drought than formerly, and on the other hand, to sudden and disastrous inundations.

Mauritius, which was formerly a very productive island, and exported considerable amounts of sugar, and was noted for the salubrity of its climate, has been nearly ruined as to its productiveness, and its climate changed so that it has become a hotbed of malaria, because of the destruction of its forests. The Island of Ceylon, and several of the important West India Islands, have been greatly damaged in the same manner; in fact; these instances of injurious effect might be continued almost indefinitely.

Among the results of excessive clearing are the great general meteorologic changes which have adversely affected a vast proportion of the earth's surface, thereby increasing the prevalence of disease and cutting short the duration of human life by the greater accumulation of heat over extensively denuded surfaces, and the increased force and velocity of the wind and sudden changes of temperature resulting therefrom, the increase in frequency and in extent and violence of cyclones and tornadoes being sequences and effects of the same disturbing cause. And it is now pretty generally understood that the destruction of the forests, especially over the mountainous and hilly regions, where the streams have their sources, is the cause of the growing tendency to increased river flooding in the several respects of frequency, more rapid rising, greater volumne and force of current, as well as in exteut of inundation, with proportionate increased disaster to the countries and communities involve 1 ; the increased prevalence and increased extent of malarious and other diseases, caused by the greater area of land submerged, as consequences which follow later, not being usually included in estimates of damages in such cases. While the scope of this paper will admit of but a small number of the illustrative accounts, and but little of the detail in description and circumstances, yet the investigations are sufficient to prove that the excessive and very general denudation, has been the principal cause of the great physical decadence and injurious meteorologic changes which have been sustained.

When rain falls into a forest, the descent is broken by the limbs and foliage of the trees, and the fallen leaves and other forest litter covering the ground farther protects it from the packing effect of a heavy rainfall, and at the same time restrains the water from flowing off, and the permeable vegetable mold, formed of the decayed leaves and twigs serves as a sponge to hold it upon the firmer soil beneath until it is gradually absorbed, and the roots of the trees conduct it on down into the subsoil. And sometimes the 
roots themselves will penetrate through subsoil so compact as to be nearly impervious to water, and lead it below into more porous strata. And thus is the water stored during seasons of superabundance, to break out in springs at points of lower elevation, where the stratum it rests upon, reaches the surface, or to be raised again as required, through the roots and bodies of the trees, and exhaled by the leaves, to perform its office in equalizing the moisture and temperature of the atmosphere.

On the other hand, the open field is exposed to the full force of the elements, and by the beating of the heavy storms, followed by the rapid evaporation from direct exposure to sun and wind, the soil becomes baked and hardened, and when the rain falls there is a tendency to gather into pools and puddles on the surface, or it runs off, carrying the finest particles of soil with it, and on sloping lands channel-ways form, by which the water is the more rapidly conducted to the streams; and although plowing makes the ground permeable to the depth which the plow reaches, yet wherever there is grade sufficient to establish a current, it also favors the washing away of the soil.

To illustrate effects, under different conditions, we will take as an example two converging water-sheds, embracing a large area of country which is traversed by streams having their sources in the surrounding high lands, and emptying into a larger stream, the common outlet. In case of a heavy rainfall, in the natural wooded condition, the greater part of the water is retained and absorbed, and what is not thus disposed of sipes away so gradually, and carries so little of earthy substance with it, that it but slightly discolors the streams into which it runs, and does not fill the channels beyond their carrying capacity, and the level country along their banks presents no appearance, by abraded surface, deposits of sand and gravel, or by other violence to nature, to indicate the actions of previous floods, and as dry weather sets in, the forest trees draw from their ample stores the moisture which gives them life and clothes them with verdure, until the close of the season. But let the same country be completely stripped of all its timber growth, and the water of each succeeding rainfall finds its way into the river channels with increased rapidity, as the soil of the naked land grows each year more and more impermeable, and as the channel-ways become more completely cut out, and the dark flood, as it sweeps over the valley farms and submerges the bordering towns, bears on its bosom to the sea and deposits on the fields, in the streets, and in the buildings on its course, and in the channels of the rivers, preparatory for the more extended flood to follow, that which, over the country from which it has been gathered, represented millions in life-sustaining food, in successive crops of grain, of vegetables and of fruits, and during the ensuing summer the streams and springs become dried up and the soil fails to furnish moisture to the growing crops, which dwart and shrivel because that which was given in due season has run to waste. And this is the commencement of annually decreasing harvests, until the starving inhabitants commence to migrate to other countries in quest of food, and through the increasing sterility, in the course of time, the whole region becomes au uninhabitable desert.

This is but a pen picture of what has already taken place over an immense area of the earth, either according to the full representation or in degree, and is simply the inevitable result of the violation of Nature's immutable laws. It is true that a large proportion of land is required for the produc- 
tion of breadstuffs, fruits, vegetables, and pasturage; but the shelter and equalizing influence of forests are equally important, and in countries where the wind currents and meteorologic conditions are such as tend to a scant and uncertain supply of rain, the maintenance of a certain proportion of woodland is a prime necessity, in order to insure the fruitfulness of the cultivated lands, and to obviate the gradual dessication and deterioration which are sure to follow excessive clearing.

Although the early history of the European nations exhibits a great deal of vandalism, and of wastefulness as to the natural resources of their respective countries, and even in later centuries a lack of wisdom and forethought to take steps to avert very serious consequences, yet after having already suffered occasional want and scarcity of food supply, and having been confronted by the grave problem for the immediate future, they find enforced upon their attention that which has been ignored until quite recently in the past, and which may be stated as follows: How to use the earth without abusing it; or, more perspicuously, how to make a living off the lands in our possession, without impairing their productive capacity, or deteriorating the climatic ecnditions, in our own day, or for those who are to hold the title deeds after us? And we may hope that the energy of the Uancasian race, and the greater enlightenment of modern civilization may, with some degree of success, be able to cope with the situation.

Forest preservation and forest restoration have been receiving a great deal of attention in some of the countries of Europe, during the last quarter of a century, and most European countries have enacted eftective laws for forest protection, and much greater advancement has been made in forestry, in several of those countries, than in the United States. And the fact that forests are there largely held by the respective general and municipal governments, gives opportunity of carrying out measures of forest restoration with less impediment than could be done with conditions of ownership which prevail in this country, although in France and in some other European countries, the governments assume control of private forests, to limit the extent of cutting, and to enforce replanting in forest trees whenever it is thought the public interests require it.

The French Government has done a great deal in the way of reboisement, or the restoration of woodlands on denuded tops and slopes of mountains, to arrest the erosion by torrents, which was ruining the lands of the valleys, with rock, gravel and other debris which was being carried down over them. The law of reboisement was passed in 1860 , which enables the government agents to take possession of private lands wherever so situated that it is necessary they should be included in the plans of restoration, and in sixteen years from the commencement on the Alps, on the Cevennes, and on the Pyrenees, 63,168 acres had been successfully replanted at an enormous cost, but the whole expense was less than the clamage which might have been produced by a single flood.

The Governments of Italy and Switzerland are following the example of France in measures of reboisement.

The Prussian Government, with other steps for the advancement of forestry, has passed laws to encourage the formation of forest companies where the situation is such that tree planting and cultivation can be carried 
on to better advantage by association than by individual effort, and municipal governments are also encouraged to engage in the work of restoration.

The maritime nations of Europe have given much attention to the reclamation of the sand dunes, and to arresting the movement of the drifting sands of their sea coasts on to the arable lands adjoining and toward the interior. The first recorded efforts in this direction were commenced in Denmark and in France about one hundred years ago, and have been continued since, in France, on a more extensive scale than by any other nation.

The engineer Bremontier, after having devised methods of restraining and fixing the sands, undertook, under the patronage of the French Government, the planting of maritime pines, which he carried out with great success. The Department of Gascony had one hundred miles of sea coast covered with sand dunes, extending from four to eighteen miles in breadth, back from the beach, and some of the dunes were hundreds of feet in height. Under Bremontier's superiutendency all this region was covered with forest growth, and since his time, the work has been continued by the French Government, and at the present time over the whole line of the French Atlantic Coast, one hundred thousand acres of forests, valuable for their productions of turpentine, resin and timber, have been added to the national resources, and a still greater quantity of valuable agricultural land has been rescued thereby from the certain destruction with which it was threatened by the advancing sand hills. Ana adding to this the beneficial effect upon the climate to the interior by this broad balt of pine timber as a protection from the ocean winds, it will be seen that the results achieved are of very great importance.

George B. Emerson, in a report on the trees and shrubs growing in the forests of Massachusetts, states: that in 1872 he visited the region saved by Bremontier, and that, in the midst of the recovered region, he stopped a day or two at a beautiful town where a hundred thousand persons from Paris and other cities of France, attracted by the genial climate and health giving atmosphere of the pine forests, had passed the Winter. He also states that he saw in many places deciduous trees, oaks, ashes, beeches and others, growing luxuriantly under the protection of the pines.

Schools of forestry have been established in several countries of Europe, and in Germany special plans of training have been adopted, including the acquisition of practical experience by devoting a certain time to manual labor in tree planting and timber cultivation under the direction of skilled instructors, and graduates of these institutions are eligible to government appointments or to enter the employment, as superintendents, of other parties. 'There are nine schools of this description in the German Empire. There are several countries in Europe, also, where stations are kept up by the governments for making meteorologic observations to ascertain the comparative conditions of atmosphere, rainfall, etc., as between forest-covered situations and the open fields.

In the United States, forestry is an industry of recent introduction. Congress has passed laws intended to encouruge tree plauting on the public lands, but without extensive results as yet. But the able and very efficient Chief of the Forestry Division of the Department of Agriculture, has col- 
lected and made public through his several reports a vast amount of useful information which, with lis many valuable suggestions, is directing attention to the greatimportance of the subject, and is operating as a stimulus in the development of this neglected branch of agriculture. About one-half of the several States of the Union have passed laws to protect and encourage tree planting along the highways, some of them granting a certain amount of exemption from taxation therefor, and a small number have provided cash bounties for successful timber cultivation. The State of California gives one dollar for each thrifty tree planted along a highway, after four years growth. But the association of individuals for the promotion of forestry has apparently effected more than has been accomplished, directly, by State or Federal legislation.

In Minnesota, a State Forestry Association has been formed for the encouragement and promotion of forest culture, by the collection and diffusion of information on that subject, to secure the general observance of arbor day throughout the State, and to promote the ultimate redemption of the treeless regions of Minnesota. This Association gives premiums for the enconragement of tree planting, in which it has been aided by legislative appropriation.

The Iowa State Horticultural Society began, in 1872 , to offer premiums to encourage tree planting, and it has printed annually, for gratuitous distribution among planters, a pamphlet containing directions for procuring, storing and planting of seeds, cuttings and plants, with hints on best species and varieties, modes of culture, etc., for artificial forests and shelter belts in that State. This Society has also received State aid.

In the State of Ohio, in January last, a socicty was formed to be known as the Ohio State Forestry Association, the object being to encourage the protection and planting of forest and ornamental trees, and to promote forest culture-the seat of the Society and place of business to be at Cincinnati, with provisions for branches in the different counties of the State; the Presidents of such brauches to be ex-officio members of the State Association.

The first national association for the promotion of forestry was formed in 1875, as the American Forestry Association, of which Dr. John A. Warder, of Ohio, was elected President.

Among the guests invited by the Government to participate in the centennial anniversary of the surrender of Lord Cornwallis at Yorktown, in the fall of 18s', were seven Prussian army officers bearing the name of Von Steuben, and representing the family of General Steuben of the American Revolution. One of these officers was, at the time, Superintendent of Prussian Crown lands. This gentleman, in the course of a journey through the country, had noticed the waste and neglect in the matter of American woodlands, and, when at Cincinnati, took occasion to mention the urgent need of measures for their conservation and renewal. This is believed to have been the first incident in the movement which led to a call for a Forestry Convention at Cincinnati, to be held on the 25th of April, 1882, and the following fonr days. Many citizens of Cincinnati were active in making preparations for the Convention, and funds were raised to defray the expenses. An immense number of invitations were seut out to all parts of the United States 
and Canada. Governor Foster, of Ohio, appointed the 27 th day of April as "Arbor Day," and Eden Park, in Cincinnati, was designated as a place for planting a great number of memorial trees in honor of distinguished persons living and deceased. The Convention was largely attended, and its exercises were conducted with harmony and enthusiasm, and the results eminently satisfactory - the most important being the organization of a permanent association to be known as the American Forestry Congress.

An adjourned meeting of the American Forestry Congress was held in Montreal in August, 1882, at which time delegates were present from the American Forestry Association, and this last-named Association then became merged in and united with the other movement.

The annual meeting of the Forestry Congress for 1883 is to be held at St. Paul, Minnesota, in August.

This American movement was evidently inaugurated from the most patriotic and philanthropic motives, and the gentlemen who participate in it are men of learning, character and influence, of different sections of the United States and of the Canadian dominions; and I regard it as a most hopeful sign of progress, and anticipate that by enlightening the people in regard to these matters, and by the influence and example of its members, the American Forestry Congress will lead in rescuing this country and this continent from the degree of ruin which has befallen so large a proportion of the territory of the older countries.

In the States of Minnesota, Nebraska, Iowa and Kansas, forest culture is making encouraging progress, and on many of the farms, shelter belts and tracts of timber are becoming a part of the system of agriculture. Two artificial forests are reported from Kiansas, of 500 acres in each.

Timber culture is also receiving attention in Illinois, and, to some extent, in other States.

Some of the Eastern villages have been finely improved in the matter of shaded aremues and tree and shrubbery adornment, through the organization of village improvemeut associations, and it has been found that better results are attained by this concerted action than by individual effort.

The United States is lamentably deficient in agricultural schools, and as to schools of forestry there is but one in America which can be appropriately so named. Harvard University, from endowments provided by the wills of two deceased citizens of Massachusetts-Benjamin Bussey, of Roxbury, and James Arnold, of New Bedford-has a professorship of tree culture, and an aboretum of 137 acres connected with it; but it is doubtful if this endowed school imparts as thorough practical knowledge in that department as the training schools of the other continent.

The State of California extends from $32^{\circ} 3 \Sigma^{\prime}$ to $42^{\circ}$ north latitude, being about 800 miles in length, and 190 miles in average width, with 1,097 miles of sea coast; and its western border is occupied by a range of mountains which reach in places quite to the ocean and form a walled line of sea coast, and at points project promontories beyond the coast line, and at other places recede enough to leave strips of level land and small valleys between the foothills and the ocean shore; but the general direction is parallel with the 
coast. This coast range extends nearly the entire length of the State, and its snmmit varies from 2,000 feet to about 6,000 feet, for the highest peaks, the altitude not being sufficient to retain the snow, as Summer approaches, which covers it at times during the Winter season; but it serves as a barrier against the ocean fogs and the excessive force of the sea breeze, greatly modifying the climate of the interior favorably as to bodily comfort and the production of semi-tropic vegetation. And as if nature in this formation had in view the greatest economy of space combined with commercial convenience and climatic effect, planted this range in timber growth suited in part for fuel and other domestic uses, and in considerable extent with a most magnificent forest tree not found elsewhere, and especially adapted to its situation, thus increasing the capacity of the range as to its climatic influence, and furnishing at the same time an accessible supply of excellent timber and lumber.

It would be desirable, both with reference to the saving of transportation and as to the meteorologic effect, were the surface of the interior valleys alternated with a greater proportion of timber growth; but with the limited area of forest witlin the boundaries of the State it is distributed to the best advantage for the permanent interests of the population, as the reserve or remoter forests of the Sierra Nevada cover the snow which falls copiously during the Winter season in that elevated region, and restrain its rapid melting and the torrential swelling of the streams and attendant disastrous consequences which would result were the extensive area of the upper western slope of the range a bare surface; and the snow thus held to go off gradually in the shade of the forests serves as a lasting and permanent source of supply to the streams of this region, which water a large proportion of the valley lands of the State. And these forests, and the timber and brush on the slope lower down, contribute in other important respects to the preservation of the lands both of mountain and valley, and to the accumulation of moisture and the conservation of the water supply, as is proven by meteorlogic observations in similar situations, and by the results of forest destruction in the mountainous regions of the old world.

C. F. Reed, Esq., at the time President of the State Board of Agriculture, in 1868, estimated that a twentieth part of the State was covered with heavy timber, and one-eighth, more or less, with trees of some kind; that within twenty years at least one-third of the whole native supply of accessible timber had been cut off and destroyed, and that judging the future by the past it would only require about forty years more to exhaust the entire present supply. Dr. Gray and others have corroborated the opinion of Mr. Reed; but Dr. A. Kellogg, in a brief article included in the last report of the State Mineralogist, expresses a more hopeful view, saying: "It is evident that the question of timber supply is one about which we need have little care or anxiety, if only our resources in that direction shall receive careful husbandry." "But whilst I shall not express an opinion as to which of these somewhat conflicting views is nearest correct, I think, however, that Dr. Kellogg has not calculated the full extent of the probable future market of the Sierra Nevada lumber; as, instead of going no farther east than the Wahsatch Mountains, as according to the doctor's calculation, the eastern lumber resources are so rapidly diminishing that, in my opinion, the time is not distant when California sugar pine will bear transportation and find market in localities even to the eastward of the Rocky Ilountains. 
For building purposes, the supply of stone and material for bricks is apparently inexliaustible, and iron can be utilized in that direction to a greater extent than it has been hitherto; and as timber and lumber becomes scarce and high priced, communities economise in their use.

By the adoption of no-fence laws, and by largely substituting iron wire for lumber, the amount of lumber and timber being used for fenciug at the present time is rery small as compared with its use for that purpose thirty years ago; and other materials have taken the place, and can still further be made to take the place, of timber and lumber for many purposes without serious detriment. And it is also reported that compressed straw furnishes as good a material for lumber as is manufactured from wood.

As to fuel, uature at a period when none of earth's inhabitants were sufficiently advanced to require its use, buried of its superabundant products vast stores of fuel to supplement the surface supply in this later period, as might be needed by its teeming population; and the study and investigations of chemists and inventors are already opening out an unlimited store of heat and artificial light which has been long known to exist in one of the most abundant elements of nature but which has hitherto remained locked up from our use for those purposes from a lack of knowledge of a method of obtaining and applying it with economic profit. Through the kindness of Dr. James Nevins Hyde, of Chicago, I have received a communication from Henry C. Rew, Esq., a gentleman who is connected with a company which is now lighting the west division of that city with a kind of gas just brought into use; and works are being constructed at the Elgin watch factory to furnish gas for lieating purposes by the same company. The gas used for heating purposes is water gas, which is manufactured by decomposing steam into its constituent elements, oxygen and hydrogen, by bringing it into contact with incandescent carbon. Water gas burns with intense heat, and Mr. Rew states that there is every reason to believe that it is to become the fuel of the future, as one ton of coal ntilized in manufacturing the water gas supplies as much heat as four and one-balf tons by direct combustion, with the additional advantage that water gas burns without smoke. The lighting gas of this company is manufactured by charging the water gas with sufficient petroleum to make it illuminating. An inexpensive process, as this is claimed to be, which increases the heating power of coal four hundred and fifty per cent. may certainly be classed among the important and most useful of modern discoveries.

So that, after having studied over the situation and the circunstances bearing upon these questions, I conclude that although an abundant and cheap lumber and fuel supply is desirable, yet, with the economy which is practicable and the substitutes which are abundant as regards the former, and the modern available means of distributing the great supplies of the latter, with the multiplication of those resources by the late discoveries, including the use and application of electricity, and the facility and certainty with which it has been demonstrated that the farming communities can produce supplies for themselves upon their own homesteads, and that although wastefulness of any of earth's supplies of necessaries is not justifiable, yet that the means of shelter and housing, and lumber for the necessary uses of the world's population, and the supply of fuel for the purposes of personal comfort and domestic uses ; the creation of artificial light wherever required, and for the production of the great power which keeps up the busy hum 
of the machinery of the earth's industries and the world's commerce, are so much in excess of the earth's prospective future food-producing capacity that there need be no particular concern at this period in that direction; that the great terrestrial questions for the future populations, will be the questions of food and of clothing; and as the accumulation of population favors the development of disease ; and as the ignorance, improvidence, and wastefulness of the past has greatly deteriorated the earth's general salubrity and sanitary condition, questions of combatting disease and of sanitary reform will also keep pace with those of primal necessity.

Over the greater proportion of the agricultural districts of California there is a liability of receiving a less amount of rainfall in the winter months with the excess of eraporation which may follow during the growing season than is required to mature the crop ; and this being an understond fact, the conditions are therefore a commendable object of study and observation, with the purpose of devising means of successfully combatting this, the greatest natural enemy of our industrial and permanent prosperity. And considering these circumstances, the proportion of woodland in this State was too small when it first came into the possession of the American people ; and we have to regret that instead of watching and preserving the area as we found it, the denudation has been extended and the limit of woodland still narrowed down.

The early miners accomplished a proportion of the extensive destruction on the west slope of the Sierra Nevada. Without restraint of law, except of their own making, their temptations were great, and they were so wrapped up in the pursuit of the coveted gold that they were uumindful of other considerations. But the other causes of destruction are in part still continued down to the present time, and these should be looked after and arrested, especially that of careless and reckless fire-setting, which is reponsible for much of the destruction, with nothing whatever to show in return for the loss.

On the Coast Range there has also been a marked diminution of the timber area, both of the wooded lands which were looked to for fuel supply and of the redwood forests; and the' destruction from fire there has also been immense.

S. P. Pharis, who has been engaged with the industries of the redwood forests of San Mateo County for thirty years, mostly in shiugle manufacturing, and as a proprietor of considerable tracts of timber lands, has furnished the following statement:

"We have fires in the timber nearly every year, more or less. The most destructive forest fire in San Mateo County occurred in November, 1880. The destruction of sawing timber and other property by that fire caused a direct loss of fifty thousand dollars, and I estimate that the damage done by stopping the growth of pine, redwood and tanbark oak, and by killing the second growth of different kinds of wood that in a few years would have been of great value, to have been as much more-making the total loss one hundred thousand dollars. There was a very destructive fire in the forests of Santa Cruz County the same year. The last forest fire in San Mateo County occurred in the Fall of 1882 . I have worked in the redwoods of this county for the last thirty years, and I think I can say that the bulk of timber destroyed by fire would equal that which has been made use of, 
although not of as much value, yet as much as one-third of it was good sawing timber, And from what I have heard and know the same estimate might be applied to the timber of Santa Cruz County."

So much of forest fires in San Mateo and Santa Cruz Counties alone, the timbered area of which forms but a small part of the forests of the Coast Range.

Our present State laws for the prevention of forest fires are nearly inoperative, for the reason that there are not officers or men employed to see to their enforcement; and it is quite apparent that our forests will not receive the protection commensurate with the interests involved until an efficient system of mounted patrol during the dry season is adopted, which might be done by the passage of a law granting authority to organize districts in which to elect officers empowered to employ suitable men to see to the enforcement of the regulations regarding the building or lighting of fires in forests, with power to make arrests should it become necessary, ta extinguish fires, and to call out assistance in case of its being required.

In a paper presented to the California Academy of Sciences by Dr. Henry $\mathrm{N}$. Bolander, in October, 1875, occurs the following:

"Another beneficial feature of the sequoia sempervirens is the great power it possesses in condensing fogs and mists. A heavy fog is always turned into rain, wetting the soil and supplying the springs with water during the dry season. Springs in and near the redwoods are never in want of a good supply of water, and crops on the Coast Range are not liable to fail. It is my firm conviction, if the redwoods are destroyed - and they necessarily will be if not protected by a wise action of our Government-California will become a desert in the true sense of the word. In their safety depends the future well being of the State. They are our safe guard. It remains to be seen whether we shall be benefited by the horrible experience such countries as Asia Minor, Greece, Spain and France have made by having barbarously destroyed their woods and forests. But with us it is even of a more serious nature. Wise Governments would be able to replace them in those countries, but no power on earth can restore the woods of California when completely destroyed."

Anl yet the warnings of Dr. Bolander, Dr. Asa Gray, and other, learned and competent men who have investigated this subject, have not received attention to produce any effective results. It would, indeed, have been of inestimable advantage to the permanent welfare of the State had our Government have profited by the experience of the nations of the old world and have applied the present enlightened course of forest management of certain European nations herein referred to in that connection to the preservation of the limited timber tracts of this State. The forests of both mountain ranges should have been surveyed off and their boundaries conspicuously defined, and then turned over to the State Government, with certain restrictions, to be kept as perpetual timber preserves, the timber to be cut only in accordance with certain legally established rules; to leave uninjured all trees under certain dimensions, and ou payment to the State of taxes to be applied to defraying the expense of the surveillance, the maintenance of a forest police, and the work of tree planting in any localities within those boundaries which were bare of timber; with a reserve to the Goverument of tim. ber for Government uses, and, in acknowledgment of its joint suzerainty, the 
privilege of levying a light duty on all lumber exported. Such an arrangement, with laws regulating the use of the preserves as stock range, and only on payment of State tax therefor, and prohibiting such use when or in such manner as might prove detrimental to the timber growth, would have insured a lasting supply of forest products to the people of this State, and what is of much more importance, would have been an eflective guard against detrimental changes and irregularities in the water supply and in the meteorologic conditions which the destruction of the forests wonld entail. But that opportunity has been lost, as nearly all the timber lands within the State have already passed into the ownership of private parties or of corporate companies.

At its last session, the Legislature of the State of New York passed an Act providing for a State park, to be known as the Adirondack Park, to be constituted of the country around the headwaters of the Hudson, and also including a large region drained by the Black, Indian, Oswegatchie, Grass, Racket, St. Regis, Salmon and Ausable Rivers. The principle object of this Act is the purpose of preserving the forests in order to the maintenance of the waters of those streams for the supply of canals and for hydraulic power. The State owns only a part of the lands within the boundaries of the proposed park, but by withholding lands from sale for arrears of taxes, and by acquiring otherwise, as favorable opportunities may offer, the intention is to add to the State's holdings as fast as practicable.

In Wisconsin there is a project on foot of forming a State park of the country including the headwaters of the Chippewa and other rivers. And in Minnesota, of preserving in that way the forests of the headwaters of the Mississippi. And as in California the destruction of the forests would involve the destruction of every other important interest, and as the entire population is therefore jointly and severally concerned in their preservation, by the desire which all should possess for the welfare and assured means of subsistence of their children and their posterity, and for the future prosperity and greatness of the State, the forests of the State should be brought within the security of State control, and not left to the chances of individual interests and individual caprice. A survey should be made and lines established on both sides of the western or timbered Coast Range, defining the forest limits, and a line established on the west slope of the Sierra Nevada, leaving the forest belts to the eastward, and the State line might serve in part as the eastern boundary; and within those limits the State should acquire the lands as opportunities should occur, by forfeit for non-payment of taxes, by purchase whenever offered at low figures; and probably the United States Government would cede to the State for such purpose whatever tracts might not have been disposed of, and individuals might donate tracts, after having stripped off the valuable timber, which in time, if protected, would grow up in timber again, aud replanting might be resorted to where necessary. And as the State continues whilst the lives of individuals terminate, it could afford lo wait for such opportmuities, until in the course of a generation or two it would have acquired all the territory within those boundaries as Public Forest Reservations.

Having spent a good deal of time in traveling about, and in sojourning at different points in this State in studying the geographic and climatic conditions, I will now make some suggestions as to what might be done to in- 
crease its agricultural resources, to favorably modify its climate and to improve its scenery.

The great interior valley of the State is about four hundred miles in length and nearly fifty miles in arerage breadth, and being almost destitute of timber the wind sweeps down over it from the north without any effective check, and at times of low temperature, when in full force, produces discomfort to animal life and retards the growth of vegetation; and its dessicating effect upon the soil and crops during the Spring and first of the Summer months is frequently the cause of great damage and sometimes of complete crop failure. And when the crop has arrived at maturity, its force is such as to interfere with the labor of harvesting, and not unfrequently produces great waste by threshing out the ripened standing grain.

The following paragraph, taken from the Colusa Sun of June 12.1880, is an illustration of the damage which may be done by the north wind at the approach of harvest time:

"We will not get over half as much for our wheat as we would have gotten if all things had continued as favorable as they were three weeks ago. That was the best prospect we ever saw, and the county would have averaged twenty-five bushels to the acre. There are, at the lowest calculation, 300,000 acres in wheat, which, at tweuty-five bushels, would give us 7,500,000 busbels. We shall be highly delighted if we gather as much as 4,000,000 bushels even of the shrunken wheat, which we shall have to put on the market at a reduced price. We placed the loss last week at $\$ 1,000,000$, or over, but the difference to Colusa County between the full crop which we expected and what we will be likely to get will be, even at the low price we anticipate, between $\$ 2,000,000$ and $\$ 3,000,000$. And the wind is still blowing. The ripe grain is being threshed out, and that which is still green, shriveled up. Tehama, Yolo, Sutter, Solano, most of Butte, and the San Joaquin Valley, are in precisely the same condition. The wheat crop of the entire State will be cut short nearly one-half in value by the continued north winds."

It is entirely within the means of human agency to effect a great change in regard to this disagreeable and very unprofitable feature of the climate of that valley. Could belts of timber of forty rods in breadth be extended across the valley, with intervals of seven-eighths of a mile between for cultivation, it would produce very beneficial results. On account of the increased porosity and absorptive eapacity which the soil would soon acquire through the permeating and lifting effect of the network of roots, and other favoring circumstances whiph are present when land is covered with timber growth, so much greater proportion of the rain-fall would be retained and stored in these forest-covered strips as to give them to some extent the charter of reservoirs, which, being protected from sun and wind, would serve throughont the season by the exhalations of the leares of the trees to impart a.degree of moisture to the atmosphere. And as the dessicating effect of the wind is in proportion to its lack of moisture and its velocity, this, added to the forcible. resistance of the system of cross belts, and the increase of rainfall which might reasonably be anticipated, would so favor the production of full crops and of harvesting without waste, as to add immensely to the profit of grain and hay raising; and under those conditions other kinds of farming, such as the production of sorghum, tomatoes, melons, etc., could 
be added. Aud as the leeward during the prevalence of the objectionable winds would be on the sunny side of the timber, under the shelter of the protecting woodland, the orange, the lime, the nectarine, and other semitropic fruits would flourish where now their culture is impracticable.

The general effects which would be produced by forest planting in the Sacramento Valley are quite obvions, but as to the increase of the rainfall I will add further : An increased rainfall by the restoration of the forests, or by additions to the forest area, has been noted in several countries. Observations inade in France by A. Matthieu, Professor of Natural History in the Forest School at Nancy; by Marshal Vaillant, at the Government Forests at Fontainbleau and near Versailles; by M. Fautrat, in the forests of Hallette and Ermenonville; and observations also at Asschaffenburg, in Bavaria, and at stations in other countries in Europe-corresponding observations being made in the open fields near each forest-have established the fact that more rain falls over forests than over open fields; and it is well known that moisture of the earth attracts the clouds of vapor, and that wherever the moister air exists, there the condensation will take place most rapidly. If a current of air cliarged with sufficient vapor under favoring circumstances to culminate in a shower, is wafted over an expanse of naked sun-scorched earth, as it comes in contact with the heated atmosphere the vapor becomes rarified and expanded and passes off into infinity; but, on the other hand, if a cloud of vapor is carried over a forest, the lower temperature and the moisture of the atmosphere resting over it favors condeusation, and precipitation takes place, and the forest itself not only receives additional moisture but open country in the immediate neighborhood participates in the benefit. And then, in the case of a general rain in the Sacramento Valley, the wind blows up from the southward, and as timber belts would obstruct the north winds, so they would also retard the rain-bearing currents from the reverse direction, and by the longer time in passing enforce a greater amount of preciptation in the valley, leaving less vapor to pass on to the mountains beyoud, where the annual rainfall is so abundant that some degree of diminution would produce no injury.

The effect of a limited forest area, surrounded by a great expanse of open country, on the amount of rainfall is not appreciable; but the proportion which I have proposed would undoubtedly produce a decided influence in that particular as well as in the other respects mentioned, with the additional advantages which would follow by the modification of the extreme summer heat, protection from the cold winter winds, and the purification from all miasmatic effluvia ; which increased salubrity would be in itself an improvement that would add much to the desirability of that section for residence. And the thorough and successful cultivation in timber in that or in greater proportion, would not only greatly increase the general prosperity, but would more than double the value of the properties, and with the arrest of the progressive destruction from another source, would couvert our great valley into one of the finest regions of the earth.

There are other valleys in this State which would be benefited by giving more attention to forest tree planting. Wind-breaks would be of great advantage throughout the Santa Clara Valley, or in any part of it, for the protection to the orcharding and other farming interests, as well as by adding to the beauty of the landscape and the salubrity of the climate; and timber culture would be remunerative for the purpose of fuel where the 
supply is as remote and the price as high as it is in most parts of that valley.

The Pajaro and Salinas Valleys would both be improved by the introduction of timber cultivation. Timber belts across the Santa Clara Valley of Ventura County would redeem it from its scourge of liot winds which rush down from the Mojave Desert, scorching up its vegeattion. In fact, nearly all parts of the State which are adapted to agriculture would be benefited by a resort to artificial timber growth to a greater extent than now prevails.

To line the sides of the highways with trees is an improvement to the farms through which they pass, and a benefit to the roads and to the public; and trees set out on a line at such distances as to form posts to which boards, poles or barbed wire can be attached, have been found to answer an excellent purpose;

The waste places of all farms should be set out in timber trees, and there is a great deal of land in this State which is too poor to cultivate with profit in cereals or other farm products, which would prove fairly remunerative if planted in forest, especially in localities where lumber is dear and fuel is scarce, and the soil would improve under a crop of deciduous trees.

Forest cultivation requires an investment which does not yield immediate returns; but if the trees are set out as thick as they should be, after three years' growth the superabundant trees will make fuel, and poles for fencing and other purposes, and from that on the forest will need but little attention, whilst the thinning out necessary to make room for the increased growth of the timber yields a constant harvest which will last for a long period; and the other benefits of the forest are always present.

I have pointed out what might be done, and what would result greatly to the advantage of the State, and yet I hardly anticipate soon seeing as general a movement in that directiou as I have herein indicated and as would inure to the benefit of the people themselves immediately concerned; but if the more enterprising will take the initiative, I think that others would soon follow their example, and the subject is specially commended to the attention of gentlemen who are in possession of large tracts and of abuudant means.

The only statements which I have obtained of the cost of raising, and of pecuniary results of forest culture in this State, are certainly encouraging. The following result, by General Stratton of Alameda County, was taken from an article by Robert C. E. Stearns, Ph. D., of Berkeley, which appeared in the January number of the American Journal of Forestry:

"General Stratton planted forty-five acres in eucalyptus in 1868. Recently twenty acres of this artificial forest have been cleared to make room for an orchard, and after charging every item of cost, and a yearly rental of five dollars per acre, the ret profits, as shown by the owner, are $\$ 3,866$ on the twenty acres in eleven years."

In May, 1882, I took a look at the fine eucalyptus grove of George A. Nadeau, located seven miles south of Los Angeles City, which consists of nintey-seven acres in eucalyptus, being the largest artificial forest in the State. The seeds were sown in nursery in December, 1875, and about six 
months afterwards - that is, in May and June, 1876-the young trees were set out, and at the time I examined them, six years after the replanting, the largest trees were twelve inches in diameter, and the average from eight to nine inches, and from sixty to seventy-five feet in hight. Recently Mr. Nadeau has sent me the following definite statement of expenses, aud the present value of the timber:

Cost of trees at the time of setting ont, $\$ 7.50$ per acre; labor of replanting, $\$ 5$ per acre; expense of after cultivation, $\$ 5$ per acre; rental of land at $\$ 3$ per acre per annum amounts to $\$ 21$ per acre for the seven years; total cost per acre for the seven years' growth, \$38.50. The estimated average amount of wood on the land is thirty-five cords per acre, which is worth in that locality $\$ 3$ per cord, in the tree, giving $\$ 105$ per acre is the present value of the timber. Or the total cost of the body of timber, $\$ 3,734.50$, and the present value, $\$ 10,185$; net profit, $\$ 6,450.50$.

In a locality where fuel is of less value, there would be less profit in the production of wood; but with that growth, the cultivation would still be remunerative where wood is not worth more that half what it is in that part of Los Angeles County.

In the upper part of San Joaquin V'alley, tree planting of any kind has been attended with very little success except in connection with irrigation; but by this artificial method of wetting the soil, large tracts of that valley which formerly presented a desert-like appearance bave been changed into productive farms, on which are raised fine crops of alfalfa, corn, sorghum, and varions kinds of vegetables; and a large proportion of those irrigated lands are being covered with vineyards and orchards, the success of vine and fruit-tree growth and the production of fruits having beeu very gratifying. And to add to the future prospect of this section of light rainfall, it has been ascertained that when the land has been once saturated it requires but $a$ small amount of water, comparatively, afterwards to keep it sufficiently moist, thus leaving a surplus from the lands first brought under irrigation to be carried on to new lands; and the area of irrigated and moist lands is constantly being extended thereby from year to year.

The litigation between the riparian claimants and the colonists is a matter to be regretted, and the fact, which has been shown by experience, that trees are more likely to be injured by frost the following Winter, and the grapes and fruits are not of as good quality when the irrigation is continued until late in the season, miglit help to a solution of the difficulty, as the time of water-scarcity comes after those interests have done with most of their season's supply; and if a compromise could be effected by abitration, before a commission composed of competent disinterested men, and an arrangement entered into by consulting the interests mutually of all the parties concerned, and the matter then so fixed that all thereafter would understand their respective rights, it would be better than a continuance of the litigation and uncertainy. There are some streams in this valley which bave not been made to do much duty in the way of irrigation as yet, the waters of which might be made available for that purpose. The Tuolumne, Stanislaus and Mokelumue could all be carried in ditches so as to cover large scopes of country well adapted to irrigation; and although it might not be profitable to irrigate for the production of the cereals, yet if each farmer could irrigate a part, perhaps one-tenth of his acreage, so that he might 
raise trees, fruits, alfalfa and vegetables, it would add greatly to his resources, increase the value of his land, and be of general utility and advantage; and at the present low rates of interest $I$ think the additional income which it would bring to the land holders would be more than the equivalent of the use of the money required for the necessary improvements. Besides the advantage of the immediate increased production by irrigation, the arrest of the water, instead of allowing it to run off to the sea, and distributing it over the land, there to evaporate, with the protection to the soil by the surface-covering of vegetation, has otherwise a very beneficial effect in its general tendency of decreasing the excessive aridity of the climate of the vicinity.*

I believe there is a great future for the irrigable districts of California, but irrigation is something of which the American people have very little practical knowledge, except what has been acquired by the comparatively brief experience in this State, and the best methods of economizing, and the most suitable times of applying the water, are proper objects of everyday thought by the irrigating planter; but the question of the preservation of the sources of supply being at the foundation of their prosperity should also be made a subject of study and of watchfulness by every property owner of the valley.

Irrigation has a tendency to the development of miasma, but I am convinced that with proper management and care there need be very little cause of apprehension on that account. The surface of the land should be so leveled and arranged that the water will not stand in pools to stagnate, especially near the dwelling, and the ditches should be kept cleaned out so as to be free from decaying vegetable matter, and care should be taken to have pure water for drinking, as the use of impure water is a very common cause of chills and fever. The surface water in the San Joaquin Valley is generally unwholesome, but by boring to some depth excellent water is obtained; but in any case where it is necessary to use surface water the expedient of boiling renders the impurities inert, for which purpose an agate vessel is preferable. I'iltering does not answer the purpose, as the filter is liable to become foul from putrefying animalcur retained in its meshes.

J. B. Rumford, who has lived on Kerm Island for several years, states that during the first years of their residence there, himself and family suffered with malarial disease, but since having learned how to manage they are exempt from it. He attributes much of the sickness in that section to the use of surfice water.

Timber culture, where practicable, possesses all the advantages for the San Joaquin that it has for the northern division of the great valley, and forests, judiciously planted with reference to that object, are apparently the only remedy which can be devised against the disagreeable sandstorms

* Recently a company has been formed consisting of Cbarles Crocker, Esq., Colonel Fred. Crocker and C. H. Huffiman, Esq., of Merced, entitled the Merced Irrigating Canal Company, to ntilize the waters of the Merced river; and a canal of ample capacity is now in course of construction, from which lateral branches are to be run to cover a large area of the lands of that comty; and as soon as the improvement has sufficiently advanced, those gentlemen propose to divide mp and offer for sale large tracts of their holding, something after the plan of the Fresuo Conuty colonies. The vigor with which the work is being posecnted and the abundant means of the company, give assmrance that this much needed improvement so long delayed in that county will now soon be accomplishel. 
which sometimes prevail in parts of the upper valley; and wood-growing would certainly prove directly remunerative there under favorable circumstances.

Dr. W. J. Prather, of Fresno City, has on his farm, a few miles south of that place, a tract of eleven acres, five years set out in black locust and Lombardy poplar, which have made a very good growth, this being the largest cultivated woodland I learned of in that county.

The eucalyptus, in the Upper San Joaquin Valley, has in some places made a fair growth, whilst in other localities its cultivation has been unsuccessful. This is owing to the peculiarities of soil and to the greater degree of exposure to frosts in some situations than in others, and in part, probably, to the difference in cultivation and management; but the experiments which have been made are enough to show that the species which have been planted there are not well adapted to that interior climate.

The eucalyptus, first introduced into California by Colonel Warren, from suggestions of Baron VonMueller, has already proved a valuable acquisition for timber culture, where there has been a proper adaptability of the species planted to the soils and situations. According to VonMueller there are one hundred and twenty species of eucalyptus, and they form the principal timber growth over the greater part of the Australian continent. Some of the species attain only the dimensions of shrubbery, and among them are beautiful flowering shrubs, well adapted to ornamental grounds; and from these diminutive species there are gradations in size, up to species which produce gigantic forest trees, which rival in height the sequoias of California. And these numerous species furnish timber of different characteristics and qualities and adapted to a variety of purposes; and among the products of the native eucalyptus forests are potash, oils, tars, acids, dyes and tans. The different species grow in a great variety of soils, situations and climates, some kinds thriving in the interior arid districts, where the heat is greater than in any part of this State; other species, including those which have been most cultivated in Califoruia, are found near the sea coast, and other varieties again cover the msuntains at different degrees of altitude, up to the regions of snow and sharp frosts, and with a better knowledge of eucalyptography species of that genus could probably be selected which would be adapted to any ciesired locality within the State.

The railroad companies, by planting eucalyptus along the lines of their roads, have excellent opportunities of acquiring information regarding the adaptability of the various species. The article by R. C. E. Stearns, Ph. D., hereinbefore quoted, contains a statement by J. R. Scupham, Esq., of the Central Pacific, from which I take the following: 'The company have planted of several varieties of eucalyptus hundreds and thousands of trees along the right of way and in plantations. About San Francisco Bay all species flourish, if cultivated when young, but most growth is made by $E$. Globulus, $E$. Cornuta and E. Gigantea. In the interior valleys these species will not flourish-are not sure even to live save in exceptional places; while the $E$. Rostrata and E. Viminalis seem to do well and bear the frost. A rich soil compensates $F$. Globulus for some frost, as is evinced by its flourishing at Delano and at Chico. In a plantation of one hundred and twenty thousand trees at Tipton, Tulare County, well-cared for, nearly all the trees of the first-named group died after struggling along for two year's, while the $E$. Ros- 
trata and the like thrive, though growing slowly. The eucalyptus now being set out are selected with proper regard to local climate, soil and situation, as well as to the quality of their wood.

It is well known that forests purify the atmosphere of miasmata, but the eucalyptus possesses this useful function in a great degree. Professor Cichi, of Santa Clara College, is authority, in an article heretofore published, that Pope Pius, in 1868, gave to an association of Trappist Monks a tract of land near Rome, which was so excessively malarious as to be uninhabitable, on condition that they should improve its salubrity. The air was so bad that during the first four years the monks could not sleep on the place, but retired every evening within the walls of Rome to avoid the nocturnal emanations; yet, despite these precautions, twelve of their number died from malaria. But principally through the planting of large numbers of gum trees', the air became so changed that they were able to take up their permanent abode at their abbey, on the land. Subsequently, a law was enacted to expel certain religious orders, including this association of monks, from the country, but the Government remitted the sentence in their behalf on condition that they should set out one hundred thousand gum trees on malarions land in their neighborhood within the following ten years.

Planting with eucalyptus has been attended with great success in reclaiming malarious districts in Algeria, and attention is being directed to it as a means of reclaiming malarious provinces in Italy and in other parts of Southern Europe.

Eucalyptus timber is used largely in ship building in Australia and Tasmania, and being torredo-proof, is very desirable for piling where immersed in salt water, and for other submarine purposes.

There are several stretches of seacoast in this State where the methods of Bremontier might be applied with great advantage, and if the Golden Gate Park Commissioners had funds furnished to enable them to raise a continuous sand ridge of a hundred feet in height a few rods back of and extending parallel with the beach from the Cliff House to the outlet of Lake Merced, and fix it in its place with trees, shrubs and grasses which would thrive in that situation, a sheltered park of alternate forest and lawn, with shrub and flower-bordered lakelets, might be created to the leeward of it, such as would be the delight and pride of themselves and their fellow citizens; and if not permitted to continue until the maturity of the improvements, they might take pleasure in contemplating the benefits which would accrue to the citizens who will arise to follow in their footsteps and occupy their places.

The "Elements of Forestry," by Franklin B. Hough, Ph. D., Chief of the Forestry Division of the United States Department of Agriculture, is a book of 380 pages, and contains a great deal of general information on the subject of forestry, as well as practical instruction for the planting and care of forest trees for ormament and profit. This is a very useful work and should be in the hands of every one who is in any manner interested in forestry. A. L. Bancroft \& Co., will order the book on application, or it will be sent through the mail, post paid, on receipt of two dollars, by the publishers, Robert Clark \& Co., Cincinnati, Ohio. 
native trees.

"Forest Trees of California," by A. Kellogg, MI. D., describes our

"Eucalyptus and Forest Trees," by Elwood Cooper, Esq., gives the most complete account of the eucalyptus of any American work.

The American Journal of Forestry, edited by the author of the "Elements of Forestry," is published monthly by Robert Clark \& Co., Cincinnatti. Price, $\$ 3$ per annum.

There is no State in the American Union in which as great natural agricultural resources are to the same extent dependent on the conservation of the timber growth, and none in which forest culture would produce as important results, in which there is as much backwardness in that direction as in this State of California. The reasons for this state of things must be apparent to those who have given attention to the subject, and it will not be profitable to occupy space here in discussing them. The thing to be done by those who are already interested is to devise the best means of enlightening the people as to its utility and importance.

The few public spirited gentlemen who have hitherto been engaged in disseminating information pertaining to forestry are entitled to the respect and gratitude of their fellow citizens for their laudable efforts, bu. individual effort is not equal to the task of doing what is necessary to be clone in this field for the preservation and development of the best interests of the State, and the old adage, "In union there is strength," was never more applicable than in matters of this kind; and I believe that those philanthropically disposed would be able to render each other mutual aid and to accomplish much more by coming together and forming a State Forestry Association after the example of Minnesota and Obio.

I will close this report with sentiments and language contained in a letter received at the formation of the Ohio State Forestry Association, from that well known statesman and philanthropist, Hon. Cassius M. Clay of Kentucky. After referring to the thoughtless wastefulness of the American people in the destruction of our native forests, and the results now being experienced from the excessive denudation, $\mathrm{Mr}$. Clay writes as follows:

"What we want now is to arouse public notice to the facts, and to create societies in the several States to act under the patronage and aid of the States, and all concentrating their experience in the National Bureau of Forestry, which can unite with foreign societies and governments and make all knowledge on this subject of world-wide usefuluess. For it is not too much to say that nations have owed their rise and fall to these laws of trse growth and rainfall, and that our nation cannot live and ignore them." 


\section{PERSONAL EXPLANATION.}

By permission, M. II. Chipman, M. D., reat the following personal explanation to the State Medical Society, at its anunal meeting in April, 1883 , and which was then, by a vote of the Society, directed to be printed in the volume of Transactions:

Mr. Plesidext and Mriners of the Meincal Suciety of the Stete of Calmonisis: I wish, as a personal privilege, to say a few words in regard to the Report which I made to this Society at its ammual meeting for the year 1881.

Whilst traveling about the upper Sacramento Valley in the Fall of 1880 , for the purpose of acquiring information regarding the topography and meteorology of that section, being frequently confronted with the deposits, I became interested in the debris question. I found Mr. James McConahaney, telegraph operator at Maryville, to be very intelligent on the subject, and he was kind enough to act as my guide in examining into some of the great changes which had been effected by the filling in of the deposits, in the relative condition of the river chameis, streets, property, etc., at that city; and then on my invitation and at my expense, the gentleman accompanied me to the Smartsville mines, and to him I said that as soon as I could arrange in San Francisco to be absent for a while, I should return to that part of the country and give the subject an extended and thorough investigatiou; and that was all the under'standing I arrived at, or pre-arrangement I made with any party or parties in the Sacramento Valley. In this city, I said to the late A. C. Peachy that I was going up the Sacramento Valley to study up the debris question, to make a report upon it; but he, knowing somethiug of the extent of the subject, was incredulons as to my being able to accompilsh what I proposed doing, and exclaimed: "My God! your can't do it!" But I assured him that I thought I could unless my health failed me; and that was the full extent of the connection which any other party than myself had with the matter in this place. In fact, I was quite reticent of my intentions regarding it, as I was apprehensive that my health might give ont, and I should in consequence fail of accomplishing my purpose.

Of men of character and intelligence in the Sacramento Valley I requested information of extent of deposits, damages, etc., as affecting their own immediate localities and neighborhoods, but cautioned each one to be sure to make no statements but what will bear rigid investigation, for I had ratlier make an under estimate than to set down anything in excess of facts; and I made personal examinations as far as my time would permit, and in any case where I had doubts as to information received, I obtained other evidence, and continued to follow the matter up until I became satisfied that I had ascertained the facts. Thronghout the whole affair I was acting in 
the fear of no man, nor in the expectation of reward or faror from any man, or any party or any class or set of men whatever, and the investigation was wholly of my own conception, and was entered into without the advice of or even consultation with any person, and was carried through altogether on $\mathrm{my}$ own respousibility, and was altogether of $\mathrm{my}$ own doing, without the aid or assistance of any party or parties, except in the matter of information furnished, in accordance with the statements of the Report itself.

As to my personal expenses of steamboat fares for self aud team, and railroad fares, and hotel and livery bills and other outlays, I was everywere charged full price, and I will assure the Society that I made no claims of rebate therefrom; and those expenses as well as the subsequent expense of publishing three thousand copies of the Report in pamphlet form, and distributing through the mails, were all borne by myself.

G. G. Briggs, the viticulturist, after receiving a copy of the Report, sent me his check for twenty-five dollars, as a contribution towards reimbursement of my expenses. I re euclosed the check in a letter in which I thanked Mr. Briggs for his kind intentious, but stated that I had commenced with the expectation of doing everything at my own expense, aud that I could then swear that I had not received one dollar for that effort, and as I preferrer to occupy that position, I therefore could not accept the twentytive dollars.

The reason of my making this statement is, that a talented and prominent menber of this Society testified, on a certain occasion, in a language which exhibited that he was of the opinion that my Report on the debris question had been gotten "p in collusion with other parties, and for another purpose than that which is set forth in the Report, and with the assistance, and even the personal help of another party, or of other parties; and altt.ough the gentleman may have changed his mind in reference to the matter since that time, yet as I have never learned of his having publicly or otherwise so stated, and as it would neither be honorable in the individual, or respecttul as toward this Society, to take adrautage of a position conferred by the Society, to make out a Report professing to be intended for the pubic benefit, when in fact it was only for the benefit of the individual himself, or of a certain limited class with whom the individual was in co!lusion and interested, I lave therefore taken the liberty of making this statement in correction of any mistaken impressions which might have been entertained in relation thereto.

The life of an individual lasts only a generation, but a state is supposed to continue for sereral generations, and we may hope that this State will be in existence and prospering, a thousand year's hence, and the people of the future are just as much interested in the lands of the State as are those of the present generation; and when I saw the great amount of destruction which was being perpetrated, I concluded that they were sadly in need of a representative, and in lack of abler or more influential representation, I even assumed to do wliat I could in the premises myself, and I presumed that a reliable and truthful representation of the facts would have an inHuence in bringing about proper and equitable measures of relicf; and as my labor was performed more in behalf of the future than of the present, I was quite well satisfied to trust my compensation entirely with the future. And that was the basis of my calculation and of my action. 
The preceding Report, and the explanation regarding my Report to the State Medical Society, for 1881, were republished from the volume of Transactions of the Society, in pamphlet form, for more general distribution, in October, 1883.

M. M. Chipman, M.D.

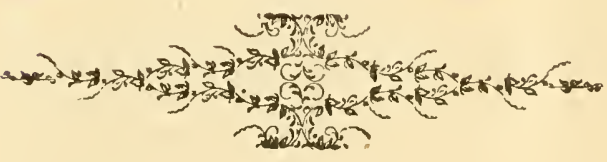






\section{LIBRARY OF CONGRESS}

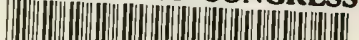

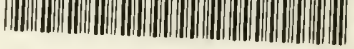

0000881855 य 